Wilkins RM. Insecticide resistance and intracellular proteases.

Pest Management Science 2017, 73(12), 2403-2412.

DOI link

https://doi.org/10.1002/ps.4646

ePrints link

http://eprint.ncl.ac.uk/241747

Date deposited

$10 / 04 / 2018$

Embargo release date

$19 / 06 / 2018$

Copyright

This is the peer reviewed version of the following article, which has been published in final form at https://doi.org/10.1002/ps.4646. This article may be used for non-commercial purposes in accordance with Wiley Terms and Conditions for Self-Archiving. 


\title{
INSECTICIDE RESISTANCE AND INTRACELLULAR PROTEASES
}

\author{
Richard M Wilkins \\ School of Agriculture Food and Rural Development \\ Newcastle University \\ Newcastle upon Tyne NE1 7RU \\ UK
}

\section{ABSTRACT}

Pesticide resistance is an example of evolution in action with mechanisms of resistance arising from mutations or increased expression of intrinsic genes. Intracellular proteases have a key role in maintaining healthy cells and in responding to stressors such as pesticides. Insecticide resistant insects have constitutively elevated intracellular protease activity when compared to corresponding susceptible strains. This increase was shown for some cases originally through biochemical enzyme studies and subsequently putatively by transcriptomics and proteomics methods. Up-regulation and expression of proteases have been characterised in resistant strains of some insect species, including mosquitoes. This increase in proteolysis results in more degradation products (amino-acids) of intracellular proteins. These may be utilised in the resistant strain to better protect the cell from stress. There are changes in insect intracellular proteases shortly after insecticide exposure, suggesting a role in stress response. The use of protease and proteasome inhibitors or peptide mimetics as synergists with improved application techniques and through protease gene knockdown using RNA interference (possibly expressed in crop plants) may be 
potential pest management strategies, in situations where elevated intracellular proteases are relevant.

Key words: Pesticide, resistance, intracellular protease, insecticide, peptidase

\section{$1 \quad$ INTRODUCTION}

Intracellular proteases degrade resident cellular proteins and peptides and also those proteins that are transported into the cell. Although their role is basically to degrade cellular proteins they are essential in maintaining the cell in balance and healthy, and they are also involved in activation of enzymes and very many other functions. The cell response to toxic stressors is part of such maintenance of homeostasis and it can be seen that intracellular proteases may have an important role in the evolution of pesticide resistance. This article aims to review the literature and explores their potential whole as stress induced enzymes and their relationship with insecticide resistance. This review will examine resistance in insects (and other arthropods) to insecticides important in agriculture and public health. Resistance to insecticides in mosquitoes is critically affecting the efficacy of control of human disease vectors and much research into the mechanisms of resistance has been done on these insects. The literature reporting changes in intracellular proteases in resistant strains of insect pests compared to their susceptible counterparts forms the basis of this review. The focus will be on this difference and the implications it could have on the characterisation and management of resistant insects. 
This review starts with a brief introduction to the intracellular proteases. The main part covers the reports on the differences between resistant and susceptible insect strains, vis-avis intracellular proteases. This is split into three parts according to the research methods used: 1 enzyme studies; 2 transcriptome analyses; and 3 other molecular methods. The protease response of insects exposed to insecticides is then considered as it may be expected to be part of the stress reaction and related to resistance. Finally, the background and opportunities to use the intracellular proteases for resistant pest management are included. Evidence for protease degradation of insecticides and the potential of intracellular proteases as targets is covered.

\section{INTRODUCTION TO INTRACELLULAR PROTEASES}

The purpose of the genome is to direct the synthesis of all the proteins that make up the structure of the cell. As this is a dynamic process, constantly varying according to the cell condition, there is a need to degrade and recycle these proteins. This is known as protein turnover and this reversal of biosynthesis is carried out by the intracellular proteases. ${ }^{1}$ Much of the nature of these processes that control this turnover have been elucidated in recent decades and this understanding is applicable to pests and their stress responses. As the action of proteases is potentially damaging to the cell, even suicidal, it necessarily is tightly controlled and well coordinated. This complex process aims to maintain proteostasis, in spite of internal changes in the state of the cell and external factors. These external factors include toxic pesticides which perturb this proteostasis and precipitate stress responses. ${ }^{2}$ These introductory remarks apply to most cell types although the emphasis will be on eukaryotic cells, especially where relevant to insects. ${ }^{3,4}$ 
Proteases or peptidases are enzymes that cleave peptide bonds in proteins and peptides by hydrolysis and have a key role in the protein turnover along with transcription and expression of the active genome. This depends on continual removal of unneeded proteins and the consequential supply of amino-acids. Peptidase types are grouped according to the position and the amino-acid residues of the peptide bond (in the peptide chain of the protein) to be hydrolysed. Thus, there are six catalytic types (serine, cysteine, metallo, threonine, glutamic and aspartic) further divided into 250 families by sequence, and these in turn are grouped into approximately 60 clans by comparing tertiary structures. ${ }^{5}$

Several mechanisms regulate peptidase activity, in addition to transcriptional and posttranscriptional controls. ${ }^{6}$ Thus, most enzymes are synthesized as inactive zymogens that are activated by suitable proteolytic cleavage and then rapidly blocked by specific inhibitors. This regulation is carried out within networks, with cross-activation of zymogens and inhibitors combining to give a cascade effect and consequently an amplification of an initial stimulus. $^{7}$

Proteolytic activity is located in a complex of structures throughout the cell, in the cytosol, nucleus, endoplasmic reticulum, membranes and lysosomes. ${ }^{8}$ There are four major peptide-generating systems within cells: proteasomes, calpains, caspases, and lysosomes. The most important of these is the ubiquitin-proteasome system (UPS); in general terms a small protein, ubiquitin, is linked to the protein to be degraded and the product enters the barrel-shaped proteasome, a complex consisting of subunits, where it is hydrolysed. ${ }^{9}$ Short-lived and damaged proteins are degraded (to peptides) and thus 
the proteasome controls basic cell processes and protects the cell from stress. ${ }^{9,10}$ The earliest identified degradative route for proteins is within lysosomes; foreign proteins and cell materials can be transferred to the lysosome by a number of mechanisms which include autophagy.

\section{INTRACELLULAR PROTEASES IN RESISTANT AND SUSCEPTIBLE STRAINS}

\subsection{Biochemical Enzyme Assays}

The first definitive report with the comparison of resistant and susceptible strains of insect pests for their intracellular protease contents was in $1994 .{ }^{11}$ This work was based on a representative range of intracellular proteases for which there were established assays using fluorogenic specific substrates. These proteases were representative of the main types, found in the neutral conditions of the cytoplasm or in the lysosomes at acid $\mathrm{pH}$. These enzymes (listed in Table 1) were explored in follow-up studies and were obtained from resistant and susceptible strains of a limited range of pest insects. A toxicological profile (especially the responses to a number of insecticides, with and without a range of relevant synergists) for each strain was made. ${ }^{11}$

The baseline status of each strain, usually the adults for the pests chosen, was determined for each of the intracellular proteases from tissue homogenates. ${ }^{12}$ Adaptation to any insecticide stress would logically modify cellular metabolic processes, especially in relation to protein turnover. The intracellular protease activities of the house fly Musca domestica, resistant and susceptible to DDT were studied..$^{12}$ In this investigation the resistant (resistance ratio: 84 ) and susceptible flies were bioassayed with a number of insecticides, 
with and without synergists, and their cytochrome P450 contents and glutathione Stransferase (GST) activities were measured (the more likely metabolic mechanisms). The protease activities of whole fly (and also body parts) homogenates were measured using peptide substrates and based on the fluorescence of the liberated 7-amino-4methylcoumarin (AMC). The results indicated a general elevation of protease activities in the resistant strain as compared to the susceptible. ${ }^{12}$ This can be seen for whole body homogenates in Fig. 1; the effect is more pronounced for the cytoplasmic enzymes where total activity significantly increased from $10.3 \pm 0.4$ to $19.1 \pm 0.2 \mu$ moles substrate hydrolyzed $/ \mathrm{h} / \mathrm{mg}$ soluble protein. It was considered likely that variations amongst the insect populations, of cellular enzyme properties, allowed insecticide selection of individuals which have the optimum biological profile. Intracellular proteases with a diversity of functions are an integral part of this.

A number of other studies of a similar nature on resistant and susceptible strains of insect pests have been made. These are based on biochemical protease analyses using the same fluorogenic substrates. Some of these are summarised in Table 1 with comments concerning the protease types that are increased or decreased in activity. Other reports on the same species (Musca domestica and Tribolium castaneum) have not been included, for brevity. From these publications the overall picture for the variation between resistant $R$ and susceptible $\mathrm{S}$ strains is that the majority of the proteases investigated are more active in the R strains. This trend is for both cytoplasmic and lysosomic enzymes and for all the (few) insects species studied, although responses varied according to protease (see Table 1). 
General conclusions from this work, are that resistant strains have elevated constitutive protease levels and this increase may not be specific to any peptidase, nor any pesticide or resistance mechanism. The changes represent the adaptation of the insect to stressors and there are many biochemical changes in the cell in addition to the effect on peptidases. ${ }^{5}$ It would appear that the role of elevated proteases in a resistance mechanism may be the increased proteolysis and production of amino-acids for the synthesis of defensive systems. ${ }^{12}$ The results are seen for a small range of species, but as they are the result of cell stress, they may well likely be common to many pest species.

\subsection{Transcriptome analysis methods}

Molecular biology methods for the study of resistance have been revealing multiple mechanism/gene-interactions. As a consequence of these investigations, genes controlling mechanisms in addition to those for metabolism and target site modification have been found. Other genes having no clear role in pesticide defence are up-regulated, including those for proteases. A complex system of multiple genes and gene interactions seems to exist showing a long evolutionary history of defence against stressors. ${ }^{17}$

Cases of resistant insects where elevation of intracellular proteases has been found, in addition to increases in defence mechanisms such as metabolism or target site modification, are given in Table 2. This is a representative listing, but not exhaustive, of transcriptomic analyses of resistant vs susceptible comparisons, where intracellular proteases are included. The increases of these proteins in the cell in these cases have been inferred by studying the RNA transcriptome. Analysis of mRNA through high-throughput expression profiling using microarrays has provided considerable advances in understanding the molecular base of 
resistance. This approach has identified genes for proteins that are up-regulated in the resistant strain. ${ }^{19}$ Further, not only is resistance imparted by genes for multiple protein upregulation, but depends on the interaction of regulatory factors. ${ }^{19}$

A comprehensive transcriptome analysis of the house fly $M$. domestica has been made, comparing a multiple insecticide resistant strain with susceptibles. ${ }^{19}$ A large number of upregulated genes in the resistant strain were found. These included the key detailed function categories; metabolism, regulation, and intracellular processes. Within the intracellular group were protease genes controlling digestive, catalytic, and proteinase activities. The function of genes in signal transduction and proteases in resistance mechanisms is less understood than in detoxification. However, the authors ${ }^{19}$ provided support for the idea that co-overexpressed genes are frequently co-regulated, and that the up-regulated proteases are part of the resistance mechanism.

A similar whole transcriptome study has been carried out on the mosquito Culex quinquefasciatus. ${ }^{21} \mathrm{~A}$ low-resistant permethrin strain (10-fold level compared to a standard susceptible) was selected over 8 generations to give a highly resistant strain (2700-fold level). In the highly resistant strain all cytochrome P450 genes were up-regulated at least by twice. The RNA sequencing identified 23 protease genes that were up-regulated, most by $100 \%$ and the remainder by 50 to $80 \%$, compared to the low resistant strain. These proteases have digestive and catalytic proteinase activities as well as involvement in the regulation of signalling transduction ${ }^{30}$ and protein trafficking in cells. Possible explanations for the up-regulation of proteases in resistant strains included 1) proteolysis of unwanted proteins for biosynthesis of metabolic enzymes such as P450 and other defensive proteins, 
2) interaction with up-regulated genes that are associated with protein trafficking and signal transduction.

The fruit fly Drosophila melanogaster has been used as a model in understanding the molecular mechanisms of insecticide resistance. Using laboratory developed strains resistant to DDT, transcriptomic studies have shown the activation of the Nrf2/Keap1 pathway in resistant insects. ${ }^{31}$ Activation of this pathway is required for insecticide induced transcription of detoxification genes in Drosophila. This pathway involves the ubiquination of the transcription factor $\mathrm{CncC}$ (the Drosophila ortholog of Nrf2) which allows for its proteasomal degradation. ${ }^{31}$ It was shown that this pathway is active in resistant strains (but not in susceptible) of Drosophila, giving rise to the overexpression of multiple resistance genes. Thus, this work showed that the Nrf2/Keap1 pathway contributes to the upregulation of xenobiotic degrading enzymes in resistant Drosophila. Inhibitors (not specified) of this pathway may offer the possibility of synergists for the control of insects. ${ }^{31}$

Other cases of research identifying the overexpression of intracellular proteases in insecticide resistant insect strains, based on transcriptomic analyses, are provided in Table 2. These examples provide indirect support for the involvement of intracellular proteases in resistance mechanisms.

\subsection{Other methods for intracellular proteases.}

Methods based upon cDNA microarrays followed by real time quantitative PCR (qPCR) to verify expression levels for some genes comparing resistant and susceptible strains have 
been used. Based on this approach a number of peptidases, including serine proteases, showed high constitutive overtranscription in a highly DDT-resistant strain (resistance ratio 647) of Anopheles Gambiae. ${ }^{32}$ It was suggested that that the peptidases were involved in the activation of immune pathways which may enhance the capacity of insects to adapt to insecticide pressure. A similar approach of microarray and qPCR was also used to compare a highly DDT resistant strain of Drosphila melanogaster to a susceptible. ${ }^{33}$ More genes were overtranscribed in the resistant strain, and a link with serine protease expression was made. In fact, there was remarkable constitutive overexpression of putative serine proteases. ${ }^{33}$ Mainly, the up-regulated proteolysis in resistant insects may help to meet energy demands and to help balance degradation and biosynthesis of proteins under stress (homeostasis). Other defensive functions that could be supported by up-regulated proteases include synthesis of antimicrobial peptides, hemolymph coagulation, immune system and melanisation of pathogens. ${ }^{33}$

Research using cDNA microarrays and reverse Northern blots, ${ }^{34}$ found, based on sequence homology, trypsin and chymotrypsin serine proteases overexpressed in a deltamethrinresistant strain ( 400 fold) of the mosquito Culex pipiens pallens. A possible explanation given was that higher levels of trypsin and chymotrypsin genes expressing more of these enzymes would lead to a greater chance of survival under pesticide pressure. ${ }^{34}$ This concept of proteases offsetting the costs of the insecticidal effects on the target insect has been shown in pyrethroid resistant strains of the maize weevil, Sitophilus zeamais. ${ }^{35}$ Serine proteases were isolated from these resistant strains and shown to be more active than those from the susceptible strain; suggesting that increased energy and amino-acid 
production would be available to the resistant insect as a result of the enhanced proteolytic activity.

A high throughput screening method based on suppression subtractive hybridization (SSH) and gene expression profiling by cDNA macroarrays aimed to understand the mechanisms of resistance to deltamethrin in larvae of Culex pipiens pallens (mosquito). ${ }^{36}$ Protease genes were characterised by homology and serine protease genes were highly expressed in the resistant strain and associated with resistance. ${ }^{36}$ In fact, trypsin and chymotrypsin were 4.68 and 4.89 times more expressed in the deltamethrin resistant strain compared to the susceptible. Further experiments with transfected cells and expression vectors for trypsin and chymotrypsin showed increases in deltamethrin resistance providing evidence that these enzymes were associated with resistance. ${ }^{36}$ These increases in proteolysis may address energy needs during stress and proteostasis maintenance. Intracellular proteases may be involved in induction of direct resistance mechanisms, both metabolic and target site insensitivity. They may also have a role in protein synthesis and modification of enzyme conformation. These intracellular proteases were important, as pest management targets, and in molecular mechanisms, resistance detection and novel pesticide development. ${ }^{36}$

Cells were cultured from deltamethrin-resistant and susceptible strains of mosquitoes Culex pipiens pallens, and from their extracts, twenty-seven differentially expressed proteins were identified by two-dimensional electrophoresis and mass spectrometry. ${ }^{37}$ Four of these were members of the ubiquitin-proteasome proteolytic pathway up-regulated in the resistant strain. It was claimed that through overexpression of the steps of the uniquitin-proteasome pathway this mosquito strain had acquired stable resistance to deltamethrin. ${ }^{37}$ 
An opposite effect occurs with Bt insecticides where the toxic Cry protein needs activation by proteases in the insect midgut. ${ }^{38} \mathrm{~A}$ proteomic approach as above was used to analyse $\mathrm{Bt}$ resistant strains of the diamondback moth, Plutella xylostella (L.), and to compare the proteome with that of the susceptible strain. ${ }^{39}$ Constitutive expression of midgut proteins was compared and serine proteases such as trypsin were found down-regulated, most likely contributing to resistance by decreasing proteolytic activation of the pro-toxin within the midgut. However, in this case the change in the proteases had a direct effect on the resistance mechanism rather than only contributing to it, as the case may be with intracellular proteases. In general, non-proteinaceous and non-peptidic insecticides are not degraded (nor activated) by proteases, except for a few pyrethroids (see 5.1)

\section{INSECT CELL RESPONSE TO INSECTICIDE STRESS}

This part will consider how cells respond to uptake of pesticides (or toxicants in general) as far as changes in their internal proteases are concerned. Pests and non-pests exposed to pesticides at sublethal levels have many transient changes. ${ }^{40}$ Differential responses tend to occur, which vary according to the cellular protein considered, when resistant and susceptible strains of a pest insect are exposed to insecticides. ${ }^{17}$ Stressed insects (exposed to insecticide) experience perturbation of the cellular protein complement and transcriptome. The literature relevant to this area is based on next generation sequencing, and other molecular biology techniques that allow identification of genes that are affected, and thus which enzymes are possibly up-regulated (or down) following insect exposure to insecticides. 
The cellular stress response is the result of attack on the cell by external forces inflicted on the cellular macromolecules. ${ }^{41}$ Many aspects of the cellular stress response are not specific to the stressor because it depends on this macromolecular damage, ${ }^{40}$ which occurs mainly through oxidation or unfolding. Cellular stress responses are complex and include molecular chaperones and proteolytic enzymes. ${ }^{40}$ Heat shock proteins (Hsps) are abundantly expressed in insects and are important modulators of stress response and vital to insect survival. ${ }^{42}$ Cells respond to stress by increasing expression of proteasome subunits by means of stress-inducible proteasome chaperones. These promote proteasome assembly during stress and help maintain sufficient levels of proteasomes that degrade denatured and unwanted proteins. ${ }^{43}$ It would appear that this enhancement of proteasomes is associated with the response of the insect cell to insecticide stress. ${ }^{44}$ For example, a Drosophila melanogaster cell line transfected with a gene for expression of a subunit of the proteasome were more resistant to deltamethrin than cells not transfected. ${ }^{44}$ This work showed that the subunit and ubiquitin (which 'tags' the proteins for proteasomal degradation), were dramatically up-regulated with deltamethrin exposure.

The cellular stress response is very complex and the role of proteases in this is far from clear, thus it is unlikely that a simple relationship with resistance and insecticide exposure may be found, especially considering the kinetics of the various processes involved. Also, experiments normally do not resolve the time variable well. Studies with fluorogenic protease substrates on resistant and susceptible insect strains exposed to insecticides showed a variety of responses according to protease types. In the case of $M$. domestica following topical treatment with DDT at 1,2 and $3 \mathrm{~h}$, both the DDT resistant and the 
susceptible strain showed significant increases of alanyl- and arginyl aminopeptidase activities. ${ }^{12}$ In further studies with the same species, but with a strain resistant to fenitrothion, proteases in resistant and susceptible strains when treated with fenitrothion showed similar patterns of changes in activity. Cytoplasmic and lysosomal enzymes showed transient increases over a few hours but some maintained the increase for 24 hours. ${ }^{13}$ No clear differentiation between the strains on insecticide exposure was seen; in other words the resistant strain does not appear to respond differently. Some studies have included exposure to a variety of insecticides to assess the role of cross-resistance in relation to the protease stress response. For example, a malathion resistant strain of $T$. castaneum when treated separately with deltamethrin, pyrimiphos-methyl and gamma-HCH showed increases of arginyl aminopeptidase and tripeptidyl aminopeptidase in the resistant strain only. ${ }^{15}$ Gamma-HCH gave an increase in alanyl aminopeptidase in the susceptible strain. All three insecticides decreased leucyl aminopeptidase. ${ }^{15} \mathrm{Again}$, no clear relationship with any of the changes in intracellular proteases for resistant insects. Some cases where insecticide treatments have differed from the insecticide to which the strain is mainly resistant are given in Table 1. These examples show the complex nature of the stress response and so far no general trends can be determined from these and other similar studies.

A later report ${ }^{22}$ concerning exposure of aphids (Myzus persicae) to pyrimicarb gave upregulation of cathepsins for the susceptible strain and with less up-regulation for the simple resistant strain (resistance mechanism kdr mutation, which causes insecticide insensibility in the nerve sodium channel). For the multiple resistant strain ( $k d r$ plus MACE inhibiting acetylcholinesterase) no peptidase up-regulation was detected. Further, RNA sequence analysis of a permethrin resistant strain of the mosquito Culex quinquefasciatus revealed 
up-regulation of resistance mechanisms, compared to a susceptible strain..$^{45}$ There were many genes relating to down-regulated proteases, carbohydrate metabolism and transport. Of a few genes that were studied in more detail, serine proteases were significantly upregulated at 24 hours exposure and even more so at 48 hours (Fig 2). Other proteases were down-regulated at 24 hours but more were up-regulated at 48 hours exposure to permethrin. ${ }^{45}$ These results seem to indicate a role for some intracellular proteases in the stress response to insecticide exposure; the affect was more pronounced in the resistant strain. However, studies in this area are in the early stages and the significance of proteases on stress responses in resistant insects are difficult to interpret. A range of conventional insecticide synergists were found not to affect the proteolytic activity in susceptible houseflies when dosed alone (no insecticide). ${ }^{46}$

There is an interesting proteomic study on the mode of action of pyridalyl, a recently discovered insecticide which needs P450 activation similar to some organophosphates. ${ }^{47}$ Using a Spodoptera frugiperda cell line, a pyridalyl resistant line was then generated and by comparing the proteomes of this and the susceptible line, a number of differentially expressed proteins were found. Proteases were not overexpressed in the resistant line. However, exposing susceptible Bombyx mori larvae to pyradilyl showed the up-regulation of three proteasome subunits, ${ }^{47}$ at least supporting increased proteolysis in the stress response.

It is of interest if insecticides may also inhibit insect intracellular proteases directly. Although, in the exposure experiments described above some proteases have been depressed (both in resistant and susceptible strains), all studies have been made in vivo. 
There may well have been inhibition but this was difficult to determine in the face of cellular processes. Where proteases have been isolated from resistant and susceptible strains of $M$. domestica, their relative characterisation was determined using standard protease inhibitors, ${ }^{48}$ but no studies were made with insecticides. Inhibition of the ubiquitinproteasome system (UPS) has been suspected for involvement in the development of Parkinson's disease. In research to show an association, some pesticides have inhibited parts of this system; for example, out of 28 pesticides (including insecticides, fungicides and herbicides) screened 11 were found to inhibit $26 \mathrm{~S}$ proteasome activity at $10 \mu \mathrm{M} .{ }^{49}$ Carbamate and organophosphate insecticides screened did not inhibit the UPS. However, cell-based assays were used. ${ }^{49}$ Another cell-based study showed insecticides endosulfan and dieldrin inhibited the UPS at low concentrations. ${ }^{50}$ However, in cell lysates none of the pesticides inhibited the UPS.

Thus, based on literature information it is difficult to know if insecticides in general, or even specific compounds, can inhibit intracellular proteases, or the UPS, in insects.

\section{OPPORTUNITIES FOR MANAGEMENT STRATEGIES USING INTRACELLULAR PROTEASES}

\subsection{Proteases degrading pesticides}

Generally there is no evidence to suggest that any intracellular proteases can enhance degradation of small molecules such as most conventional pesticides. However, there is some evidence that they can do this in insect digestive systems, although only for the pyrethroids. Serine proteases such as those in resistant insect strains can hydrolyse permethrin where it is known that elevated expression of these enzymes occur. ${ }^{51}$ In 
research to determine the mechanism in the insecticide resistant salmon louse Caligus rogercresseyi, high-throughput transcriptome sequencing identified trypsin and chymotrypsin serine proteases as being expressed after exposure to deltamethrin and azamethiphos. ${ }^{52}$ However, further work was required to establish the role that serine proteases had in deltamethrin degradation mechanisms of sea lice. Two deltamethrin resistance associated genes were isolated from Culex pipiens pallens mosquitoes. ${ }^{53}$ Recombinant plasmids were prepared with this resistant strain and transformed into Escherichia coli. Subsequent enzyme assays showed trypsin and chymotrypsin-like activity; both enzymes could hydrolyse deltamethrin. ${ }^{53}$

\subsection{Intracellular proteases as targets}

\subsubsection{Enzyme inhibitors}

Regulation of protein expression can occur at three basic levels. On the genetic level, the strength of a promoter determines the amount of a particular gene product. On the posttranscriptional level, stability of mRNA increases production of the protein. On the posttranslational level, glycosylation, phosphorylation, or degradation affect both intracellular levels and the activity of the protein. ${ }^{54}$ Techniques that inactivate protein expression include traditional genetic knockout or RNAi, and the use of small molecules that specifically help degrade or inhibit the target protein. ${ }^{54}$ Drugs targeting proteases have been, and continue to be, an enormous market in areas such as angiotensin-converting enzyme (ACE) inhibitors and for HIV treatments, ${ }^{55}$ as well as in infection and parasitism. 
Using proteases, and especially proteasomes as targets could find applications in pest management. Where resistant strains have been shown to have elevated levels of intracellular proteases then it may be possible to make these particular targets. Exploring this putative application may provide novel routes to overcome resistant strains or for methods that apply to susceptible strains as well. There may be applications in managing pests that have overcome resistant cultivars of crops, as resistance to crops (host plants) shares many similarities with insecticide resistance. Some studies have considered the potential for the use of proteases as pest control targets. ${ }^{56}$ A group of proteases that could provide a target in the area of pest management are the cathepsins, cysteine/aspartate proteases, especially in Lepidoptera. ${ }^{56}$ These cellular enzymes are involved in processes such as proteostasis, development, growth, metamorphosis, apoptosis and immunity and regulated by activation, inhibition, degradation, etc. Stress from virus attack, starvation, host plant defences, temperature and oxidative factors lead to their overexpression; thus this class of proteases are promising candidates as targets. ${ }^{56}$ In researching the genetic background in control with pesticides of the beetle Monochamus alternates (main vector in China of the Pine Wilt Disease), cathepsin B, cysteine peptidases, neuropeptides and serine peptidases were found to be important in growth, reproduction behaviour and other physiological processes. ${ }^{57}$ Thus, it was considered that these proteins could be suitable as targets for research into control strategies. Although a range of cellular proteins are upregulated when stressed insects become resistant, ${ }^{17}$ the selection of the proteases as targets may be a preferred starting point, although not necessarily the only option.

Protease inhibitors are widely dispersed in plant tissues, ${ }^{58}$ but these, when used in pest management, are mostly directed at digestive proteases in herbivorous pests. These 
inhibitors may also play a role in plant defence against pathogens and other pests. Also these inhibitors may be relevant where gut proteolytic enzymes in resistant strains are elevated to compensate for fitness deficiencies. ${ }^{59}$ Protease inhibitors within insects play a vital role intracellularly in maintaining proteostasis and extracellularly in hemolymph, saliva, morphogenesis, reproduction etc and in more specialised ways in silk production and blood sucking. ${ }^{60}$

The development of protease inhibitors for medical applications, ${ }^{61}$ have made available inhibitors with some potential in pest management situations. There are small molecular weight inhibitors of intracellular proteases, including those in use for virus control (e.g. inhibitors for aspartic proteases and HIV) and similar applications. A listing of protease inhibitors is available on the MEROPS website ${ }^{62}$ (http://www/ebi.ac.uk/merops). Good candidates are novel peptide structures or preferably cell-permeable non-peptidic molecules which may not be degraded by proteases. ${ }^{63} \mathrm{~A}$ range of thiourea dipeptides were found to selectively inhibit the human 20 s proteasome subunit; significantly some of these were able to reverse multi-drug resistance. ${ }^{64}$ Other second generation inhibitors for medical conditions have been progressed and could be used as starting points in understanding pesticide resistance. ${ }^{65}$

Bortezomib is a highly selective proteasome inhibitor which can induce autophagy and finds application as an anti-tumour drug. Studies of this protease inhibitor in human cells have shown changes in the balance of intracellular peptides. ${ }^{66}$ This inhibitor has been used in research into deltamethrin resistance in the mosquito Aedes albopictus. A proteomics approach was employed to compare cell lines from resistant and susceptible mosquito 
strains and to evaluate the role of the proteasome and its subunit beta type 6 using protease inhibitors. ${ }^{37}$ In this research, bortezomib, and another inhibitor MG-132, when separately applied in conjunction with deltamethrin, significantly increased the mortality of deltamethrin-resistant cells and deltamethrin resistant larvae. The evidence supported the role that the ubiquitin-proteasome system played in insecticide resistance and the authors proposed that proteasome inhibitors, such as these, may be useful as synergists. ${ }^{37}$ This reasoning has resulted in a patent application and publication for the use of MG-132, a cellpermeable, reversible and potent proteasome inhibitor, as a synergist particularly for deltamethrin and resistant diamondback moths (resistance ratio >5000). ${ }^{67}$ Topical application of MG-132 with deltamethrin on $4^{\text {th }}$ instar resistant diamondback larvae gave a significant increase of 2.19 times in toxicity compared to deltamethrin on its own. In field experiments it was claimed that MG-132, applied 24 hours before the insecticide, increased the control of this resistant insect. ${ }^{67}$ As protease inhibitors may work equally well on any species of resistant insect, and possibly with any type of resistance mechanism, the synergistic effect is likely to be non-selective in practice. Targeted application will be preferred.

Another approach to protease inhibition is through the use of peptidomimetics, which combine a peptide moiety (including those based on D-amino-acids), such as peptoids and $\beta$-peptides with an active centre. There are examples which target proteases, such as novel peptide mimetics bearing a protected aspartyl aldehyde warhead which inhibits protozoan cysteine proteases. ${ }^{68}$ A series of pseudopeptide boronate proteasome inhibitors (analogues of bortezomib) have activity on the human $20 \mathrm{~S}$ proteasome. ${ }^{69}$ This approach has some promise for parasite control but remains to be seen if it can work on insect pests. Another 
option to remove specific intracellular proteases may be through the use of small molecule PROTACs, which are bifunctional molecules that link a specific protein to an E3 ubiquitin ligase, resulting in ubiquitination of the target protein and degradation in the proteasome. ${ }^{70}$

\subsubsection{RNA interference}

Another route to apply the knowledge of the role of intracellular proteases to manage insecticide resistance may be through RNA interference (RNAi). This method for gene silencing has been explored for insect pests but presents many problems in development and application. ${ }^{71}$ Proteases are favoured amongst targets but many are not intracellular, ${ }^{72}$ although all proteases are intracellular when synthesised and before activation. In the case of a resistant insect strain the up-regulated proteases could be characterised and used as targets for knockdown. Some proteases have been the target for RNAi research in aphids. ${ }^{73}$ In the case of aphid control (and also for other herbivorous pests), there is the potential for delivering the dsRNA agent systemically through the host plant. The polyphagous green peach aphid, Myzus persicae, when moved to a new host plant species up-regulates its multigene clusters after two days. ${ }^{74}$ The cathepsin B gene family was up-regulated and when knocked down using RNA interference reduced the fitness of the aphids on the new host plant. This demonstrated the role of intracellular proteases in adaptation to stress on the new host plant, essentially similar to the effect with insecticide resistance development. The feasibility of RNAi to knockdown intracellular proteases was also shown. ${ }^{74}$

The red flour beetle, $T$. castaneum, has been used as a model insect to identify the better target genes for RNA interference. ${ }^{75} \mathrm{~A}$ large scale screen found that the proteasome was a prime target for this model insect, and would be a promising target for other pest species. 
It was also found that there was no dsRNA sequence that may not impact on other species, thus potentially this method may be non-selective. ${ }^{75}$

\section{CONCLUDING REMARKS}

There now appears to be evidence that demonstrates a difference in intracellular protease activity between insecticide resistant and susceptible strains of insect pests. This has been realised by means of studies on the expressed enzymes as well as the transcriptome and the genetic profile of the resistant compared to susceptible strains. However, further studies are needed to determine how common this is, but it has been proposed as a basis for resistance detection. ${ }^{36}$

There are many cases of molecular biology resistance research where there were no differences in intracellular protease expression. This may be because the role of proteases was not specifically investigated or that these particular proteins did not appear in the analyses. Much research using molecular biology methods has been aimed at identifying the direct mechanism(s) of resistance only. However, this increase in intracellular proteases may offer another cellular difference that some resistant strains possess (compared to susceptible) in addition to those relating to direct mechanisms of resistance (and fitness consequences). For the metabolic pathways, resistance possibly can be countered through the additional use of specific inhibitors or synergists, such as piperonyl butoxide. However, a number of traditional synergists would be needed to inhibit all of the range of degradative enzymes potentially present in resistant strains and would not be effective on the nonmetabolic mechanisms. Inhibitors of intracellular proteases may find application against a 
broad spectrum of resistance mechanisms, including polygenic. Although traditional synergists have found some successful applications, in crop protection and public health, the results have been disappointing in managing resistant pests. Better use of synergists, such as early timing of the synergist application ('temporal synergism') may improve control of resistant pests, ${ }^{76}$ and with better formulation and delivery methods (systemically) may increase the potential for use of intracellular protease inhibitors in resistant pest management. However, lack of selectivity in the disruption of proteases may be foreseen as a problem in practice and judicious use of this method against resistant pests would be needed.

Research over the last two decades has shown that up-regulation of intracellular proteases has been observed in some cases of resistant insects. There has been no clear explanation of why this should be so but it is likely to part of preparing the cell to better protect it from stress. This may be through removing damaging proteins and recycling the amino-acids for synthesis of defensive proteins, but many of the other functions suggested by various researchers may also be correct. Could this be a consequence of the adaptation to insecticide stress and selection pressure? The evolution of insecticide resistance in insects is complex but has many similarities to that in crop plants and agronomic weeds. ${ }^{77}$ It may be of interest that enhanced intracellular protease activity has been detected in weed species resistant to herbicides (atrazine \& fluazifop) and also in a rice variety resistant to insect pest attack. ${ }^{78}$ The activities of the proteases were higher (about 1.5-3 times) in both herbicide and insect resistant plant cultivars; possibly these enzymes play a part in the defence against stress in plants in facilitating the primary mechanisms of resistance. It would be interesting if this is a part of mechanisms in resistant crop plants and particularly in resistant 
genetically modified varieties. The evidence for up-regulation even extends to prokaryotes where proteases have been shown to have a role in antibiotic resistance in the bacterium Staphylococcus aureus. ${ }^{79}$

\section{REFERENCES}

1. Lopez-Otín C and Bond J S, Proteases: Multifunctional enzymes in life and disease. J Biol Chem 283:30433-30437 (2008).

2. Mehlhase J, and Grune T, Proteolytic response to oxidative stress in mammalian cells. Biol Chem 383:559-567 (2002).

3. Gilbert L (Ed.) Insect Molecular Biology and Biochemistry 1st Edition, Academic Press P. 574 (2011).

4. Hoy M, Insect Molecular Genetics, An Introduction to Principles and Applications, 3rd Edition, Academic Press, P. 838 (2013).

5. Kanost MR and Clem RJ, Insect Proteases, in Insect Molecular Biology and Biochemistry, ed. by Gilbert LI, Academic Press, London, pp. 346-364 (2012).

6. Twining S S. Regulation of proteolytic activity in tissues. Crit Rev Biochem mol 29:315-383 (1994).

7. Knecht E, Aguado C, Cárcel J, Esteban I, Esteve JM, Ghislat G, Moruno JF, Vidal JM and Sáez R, Intracellular protein degradation in mammalian cells: recent developments. Cell Mol Life Sci 66:2427-2443 (2009).

8. Mykles D L, Structure and functions of arthropod proteasomes, Mol Biol Rep 26:103-111 (1999).

9. Glickman $\mathrm{MH}$ and Ciechanover $\mathrm{A}$, The ubiquitin-proteasome proteolytic pathway: destruction for the sake of construction. Physiol Rev 82:373-428 (2002). 
10. Sauer RT and Baker TA, AAA+ proteases: ATP-fueled machines of protein destruction. Annu Rev Biochem 80:587-612 (2011).

11. Saleem MA, Shakoori AR, Wilkins RM and Mantle D, In vivo effects of lambdacyhalothrin and malathion on the proteolytic enzymes of malathion-resistant and susceptible strains of Musca domestica. Pak J Zool 26:327-333 (1994).

12. Ahmed S, Wilkins RM and Mantle D, Comparison of proteolytic enzyme activities in adults of insecticide resistant and susceptible strains of the housefly $M$. domestica $L$. Insect Biochem Mol Biol 28:629-39 (1998).

13. Wilkins RM, Ahmed S and Mantle D, Comparative effect of fenitrothion treatment on intracellular protease activities in insecticide resistant and susceptible strains of Musca domestica L. Comp Biochem Physiol 124C: 337-43 (1999).

14. Saleem M A, Ashfaq M and Shakoori AR, In vivo effect of spinosad on proteases of insecticide-resistant and susceptible strains of Musca domestica. Pak J Zool 41: 455462 (2009).

15. Saleem MA, Shakoori AR, Wilkins RM and Mantle D, In vitro effects of deltamethrin, pirimiphos-methyl and gamma-HCH on proteases in insecticide-resistant and susceptible strains of Tribolium castaneum. Pak J Zool 32:53-59 (2000).

16. Saleem M A, Wilkins R M, Mantle D and Shakoori AR, In vivo effects of cyfluthrin on proteolytic enzyme activities of malathion-resistant and susceptible strains of Tribolium castaneum. Pak J Zool 36:239-245 (2004).

17. Oakeshott JG, Home I, Sutherland TD and Russell RJ, The genomics of insecticide resistance. Genome Biol 4:202 (2003). 
18. Sagri E, Reczko M, Gregoriou ME, Tsoumani KT, Zygouridis NE, Salpea KD, Zalom FG, Ragoussis J and Mathiopoulos KD, Olive fly transcriptomics analysis implicates energy metabolism genes in spinosad resistance. BMC genomics 15:714-734 (2014).

19. Li M, Reid WR, Zhang L, Scott J G, Gao X, Kristensen M and Liu N, A whole transcriptomal linkage analysis of gene co-regulation in insecticide resistant house flies. Musca domestica. BMC Genomics 14:803 (2013).

20. He W, You M, Vasseur L, Yang G, Xie M, Cui K, Bai J, Liu C, Li X, Xu X and Huang S, Developmental and insecticide-resistant insights from the de novo assembled transcriptome of the diamondback moth, Plutella xylostella. Genomics 99:169-177 (2012).

21. Reid WR, Zhang L, Liu F and, Liu N, The transcriptome profile of the mosquito Culex quinquefasciatus following permethrin selection. PLoS ONE 7:e47163 (2012).

22. Silva AX, Jander G, Samaniego H, Ramsey JS and Figueroa CC, Insecticide resistance mechanisms in the green peach aphid Myzus persicae (Hemiptera: Aphididae) I: A transcriptomic survey. PLOS ONE 7: e36366 (2012).

23. Bonizzoni M, Afrane Y, Dunn WA, Atieli FK, Zhou G, Zhong D, Li J, Githeko A and Yan G, Comparative transcriptome analyses of deltamethrin-resistant and-susceptible Anopheles gambiae mosquitoes from Kenya by RNA-Seq. PLoS One 7(9):e44607 (2012).

24. Pedra J H F, McIntyre L M, Scharf M E and Pittendrigh BR, Genome-wide transcription profile of field- and laboratory-selected dichlorodiphenyltrichloroethane (DDT)-resistant Drosophila. PNAS 101:7034-7039 (2004). 
25. Zhang Z, Zhang P, Li W, Zhang J, Huang F, Yang J, Bei Y and Lu Y, De novo transcriptome sequencing in Frankliniella occidentalis to identify genes involved in plant virus transmission and insecticide resistance. Genomics 101:296-305 (2013).

26. David JP, Faucon F, Chandor-Proust A, Poupardin R, Riaz MA, Bonin A, Navratil V and Reynaud S, Comparative analysis of response to selection with three insecticides in the dengue mosquito Aedes aegypti using mRNA sequencing. BMC Genomics 15:174 (2014).

27. Yang N, Xie W, Jones CM, Bass C, Jiao X, Yang X, Liu B, Li R and Zhang Y, Transcriptome profiling of the whitefly Bemisia tabaci reveals stage-specific gene expression signatures for thiamethoxam resistance. Insect Mol Biol 22: 485-496 (2013).

28. Oppert B, Guedes RN, Aikins MJ, Perkin L, et al., Genes related to mitochondrial functions are differentially expressed in phosphine-resistant and -susceptible Tribolium castaneum. BMC Genomics 16:968 (2015).

29. Zou FF, Guo Q, Sun Y, Zhou D, Hu MX, Hu HX, Liu BQ, Tian MM, Liu XM, Li XX, Ma L, Shen $\mathrm{B}$ and $\mathrm{Zhu} \mathrm{CL}$, Identification of protease $\mathrm{m} 1$ zinc metalloprotease conferring resistance to deltamethrin by characterization of an AFLP marker in Culex pipiens pallens. Parasit Vectors 9:172 (2016).

30. Trejo J, Protease-activated receptors: new concepts in regulation of G proteincoupled receptor signaling and trafficking. J Pharm Exp Ther 307: 437-442 (2003).

31. Misra JR, Lam G and Thummel CS, Constitutive activation of the Nrf2/Keap1 pathway in insecticide resistant strains of Drosophila. Insect Biochem Mol Biol 43:1116-24 (2013). 
32. Vontas J, Blass C, Koutsos AC, David JP, Kafatos FC, Louis C, Hemingway J, Christophides GK and Ranson H, Gene expression in insecticide resistant and susceptible Anopheles gambiae strains constitutively or after insecticide exposure. Insect Mol Biol 14: 509-521 (2005).

33. Qiu X, Sun W, McDonnell CM, Li-Byarlay H, Steele LD, Wu J, Xie J, Muird WM and Pittendrigh BR, Genome-wide analysis of genes associated with moderate and high DDT resistance in Drosophila melanogaster. Pest Manag Sci 69 930-937 (2013).

34. Wu HW, Tian HS, Wu GL, Langdon G, Kurtis J, Shen B, Ma L, Li XL, Gu Y, Hu XB and Zhu CL, Culex pipiens pallens: identification of genes differentially expressed in deltamethrin-resistant and-susceptible strains. Pestic Biochem Phys 79:75-83 (2004).

35. Silva LB, Reis AP, Pereira EJG, Oliveira MGA and Guedes RNC, Partial purification and characterization of trypsin-like proteinases from insecticide-resistant and susceptible strains of the maize weevil, Sitophilus zeamais. Comp Biochem Phys B 155:12-19 (2010).

36. Gong M, Shen B, Gu Y, Tian H, Ma L, Li X, Yang M, Hu Y, Sun Y, Hu X, Li J and Zhu C, Serine proteinase over-expression in relation to deltamethrin resistance in Culex pipiens pallens. Arch Biochem Biophys 438:53-62 (2005).

37. Sun L, Ye Y, Sun H, Yu J, Zhang L, Sun Y, Zhang D, Ma L,Shen B and Zhu C, Identification of proteasome subunit beta type 6 (PSMB6) associated with deltamethrin resistance in mosquitoes by proteomic and bioassay analyses. PLoS ONE 8(6): e65859 (2013).

38. Oppert B, Protease interactions with Bacillus thuringiensis insecticidal toxins. Arch Insect Biochem Physiol 42:1-12 (1999). 
39. Xia J, Guo Z, Yang Z, Zhu X, Kang S, Yang X, Yang F, Wu Q, Wang S, Xie W, Xu W and Zhang Y, Proteomics-based identification of midgut proteins correlated with Cry1Ac resistance in Plutella xylostella (L.) Pestic Biochem Phys 132:108-117 (2016).

40. Kultz D, Molecular and evolutionary basis of the cellular stress response. Annu Rev Physiol 67:225-257 (2005).

41. Scott JA, The molecular genetics of resistance: Resistance as a response to stress. Fla Entomol 78:399-414 (1995).

42. Zhao L and Jones WA, Expression of heat shock protein genes in insect stress responses. Invertebrate Surviv J 9: 93-101 (2012).

43. Hanssum A, Zhong Z, Rousseau A, Krzyzosiak A, Sigurdardottir A and Bertolotti A, An inducible chaperone adapts proteasome assembly to stress, Mol Cell 55: 566-577 (2014).

44. Hu J, Jiao D, Xu Q, Ying X, Liu W, Chi Q, Ye Y, Li X and Cheng L, Identification of proteasome subunit beta type 2 associated with deltamethrin detoxification in Drosophila Kc cells by cDNA microarray analysis and bioassay analyses. Gene 582:85-93 (2016).

45. Reid WR, Zhang L, Gong Y, Li T and Liu N, Gene expression profiles of the southern house mosquito Culex quinquefasciatus during exposure to permethrin. Insect Sci (2017). doi: $10.1111 / 1744-7917.12438$

46. Ahmed S, Wilkins RM, Saleem MA and Mantle D, The action of insecticide synergists on intracellular proteases of Musca domestica L. Pak J Zool, 33: 209-212 (2001).

47. Powell GF, Ward DA, Prescott MC, Spiller DG, White MRH, Turner PC, Earley FGP, Phillips J and Rees $\mathrm{HH}$, The molecular action of the novel insecticide, pyridalyl. Insect Biochem Molec 41: 459e469 (2011). 
48. Ahmed S, Wakil W, Mantle D, Wilkins RM and Kwon YJ, Characterization of alanyl aminopeptidase from insecticide resistant and susceptible strains of Musca domestica L. Entomol Res 38: 195-201 (2008).

49. Rhodes SL, Fitzmaurice AG, Cockburn M, Bronstein JM, Sinsheimer JS and Ritz B. Pesticides that inhibit the ubiquitin-proteasome system: Effect measure modification by genetic variation in SKP1 in Parkinson's Disease. Environ Res 126:10.1016 (2013).

50. Wang XF, Li S, Chou AP and Bronstein JM, Inhibitory effects of pesticides on proteasome activity: implication in Parkinson's disease. Neurobiol Dis 23:198-205 (2006).

51. Xiong C, Fang F, Chen L, Yang Q, He J, Zhou D, Shen B, Ma L, Sun Y, Zhang D and Zhu C, Trypsin-catalyzed deltamethrin degradation. PloS one. 9:e89517 (2014).

52. Valenzuela-Miranda D and Gallardo-Escárate C, Caligus rogercresseyi serine proteases: Transcriptomic analysis in response to delousing drugs treatments. Aquaculture 465:65-77 (2016).

53. Yang Q, Zhou D, Sun L, Zhang D, Qian J, Xiong C, Sun Y, Ma L and Zhu C, Expression and characterization of two pesticide resistance-associated serine protease genes (NYD-tr and NYD-ch) from Culex pipiens pallens for metabolism of deltamethrin. Parasitol Res 103:507-516 (2008).

54. Schneekloth Jr JS and Crews CM, Chemical approaches to controlling intracellular protein degradation. Chem Biochem 6: 40-46 (2005).

55. Docherty AJP, Crabbe T, O'Connell JP and Groom CR, Proteases as drug targets. Protease and proteosome inhibitors. Biochem Soc Symp 70:147-161 (2003).

56. Saikhedkar N, Summanwar A, Joshi R and Giri A, Cathepsins of lepidopteran insects: Aspects and prospects. Ins Biochem Mol Biol 64: 51e59 (2015). 
57. Wu S, Zhu X, Liu Z, Shao E, Rebeca C-L, Guo Y, Xiong Y, Mou Y, Xu R, Hu X, Liang G, Zou S, Guan X and Zhang F, Identification of genes relevant to pesticides and biology from global transcriptome data of Monochamus alternatus Hope (Coleoptera: Cerambycidae) larvae. PLOS ONE 11: e0147855 (2016).

58. Rasoolizadeh A, Munger A, Goulet M-C, Sainsbury F, Cloutier C and Michaud D, Functional proteomics-aided selection of protease inhibitors for herbivore insect control. Sci Rep 6:38827 (2016).

59. Araújo RA, Guedes RN, Oliveira MG and Ferreira GH, Enhanced proteolytic and cellulolytic activity in insecticide-resistant strains of the maize weevil, Sitophilus zeamais. J Stored Prod Res 44:354-9 (2008).

60. Gubb D, Sanz-Parra A, Barcenaa L, Troxler L and Fullaondo A, Protease inhibitors and proteolytic signalling cascades in insects. Biochimie 92: 1749e1759 (2010).

61. Turk B, Targeting proteases: successes, failures and future prospects. Nat Rev Drug Discov 5: 785-799 (2006).

62. Rawlings ND, Barrett AJ and Finn R, Twenty years of the MEROPS database of proteolytic enzymes, their substrates and inhibitors. Nucleic Acids Res 44, Database issue D343-D350. doi: 10.1093/nar/gkv1118 (2016).

63. Patterson AW, Wood WJ, Hornsby M, Lesley S, Spraggon G and Ellman JA, Identification of selective, nonpeptidic nitrile inhibitors of cathepsin S using the substrate activity screening method. J Med Chem 49: 6298-6307 (2006).

64. Qin JM, Huang RZ, Yao GY, Liao ZX, Pan YM and Wang HS, Terminal functionalized thiourea-containing dipeptides as multidrug-resistance reversers that target $20 \mathrm{~S}$ proteasome and cell proliferation. Eur J Med Chem 126:259-269 (2017). 
65. Albekairy A, Alkatheri A and Mansour M, Inhibition of ubiquitin-proteasome pathway: A possible treatment of hepatocellular carcinoma. Int J Med Sci 5:312319 (2013).

66. Gelman JS, Sironi J, Berezniuk I, Dasgupta S, Castro LM, Gozzo FC, Ferro ES and Fricker LD, Alterations of the intracellular peptidome in response to the proteasome inhibitor bortezomib. PloS one 8(1):e53263 (2013).

67. Cheng LR, Cheng C, Hu J and Li F, Application of proteasome inhibitor MG-132 to synergist of pyrethroid insecticides. China Patent CN105961426 A (2016).

68. Ettari R, Zappala M, Micale N, Schirmeister T, Gelhaus C, Leippe M, Evers A and Grasso S, Synthesis of novel peptidomimetics as inhibitors of protozoan cysteine proteases falcipain-2 and rhodesain. Eur J Med Chem 45:3228-33 (2010).

69. Micale N, Ettari R, Lavecchia A, Di Giovanni C, Scarbaci K, Troiano V, Grasso S, Novellino E, Schirmeister T and Zappala M, Development of peptidomimetic boronates as proteasome inhibitors. Eur J Med Chem 64:23-34 (2013).

70. Bondeson DP, Mares A and Smith IED, Catalytic in vivo protein knockdown by smallmolecule PROTACs. Nat Chem Biol 11:611-617 (2015).

71. Mamta B and Rajam MV, RNAi technology: a new platform for crop pest control Physiol Mol Biol Plants doi:10.1007/s12298-017-0443-x (2017).

72. Kola VSR, Renuka P, Madhav MS and Mangrauthia SK, Key enzymes and proteins of crop insects as candidate for RNAi based gene silencing. Front Physiol 6:119 (2015).

73. Yu X-D, Liu Z-C, Huang S-L, Chen Z-Q, Sun Y-W, Duan P-F, Ma Y-Z and Xia L-Q, RNAimediated plant protection against aphids. Pest Manag Sci 72:1090-1098 (2016). 
74. Mathers TC, Chen Y, Kaithakottil G, et al., Rapid transcriptional plasticity of duplicated gene clusters enables a clonally reproducing aphid to colonise diverse plant species. Genome Biol DOI 10.1186/s13059-016-1145-3 (2017).

75. Ulrich J, Dao VA, Majumdar U, et al., Large scale RNAi screen in Tribolium reveals novel target genes for pest control and the proteasome as prime target. $B M C$ Genomics 16:674-683 (2015).

76. Bingham G, Gunning RV, Gorman K, Field LM and Moores GD, Temporal synergism by microencapsulation of piperonyl butoxide and $\alpha$-cypermethrin overcomes insecticide resistance in crop pests. Pest Manag Sci 63:276-281(2007).

77. Gressel J, Evolving understanding of the evolution of herbicide resistance. Pest Manag Sci 65:1164-1173 (2009).

78. Ahmed S, Wilkins RM, Mantle D and Begum MN, Intracellular proteases and resistance in plants. Int. J. Agric. Biol. 7:30-34 (2005).

79. Frees D, Gerth $U$ and Ingmer $\mathrm{H}, \mathrm{Clp}$ chaperones and proteases are central in stress survival, virulence and antibiotic resistance of Staphylococcus aureus. Int/ J Med Microbiol 304:142- 149 (2014).

\section{ACKNOWLEDGEMENTS}

The author is grateful to the input from Dr J Gressel and also to the anonymous reviewers for their helpful comments.

\section{FIGURES}




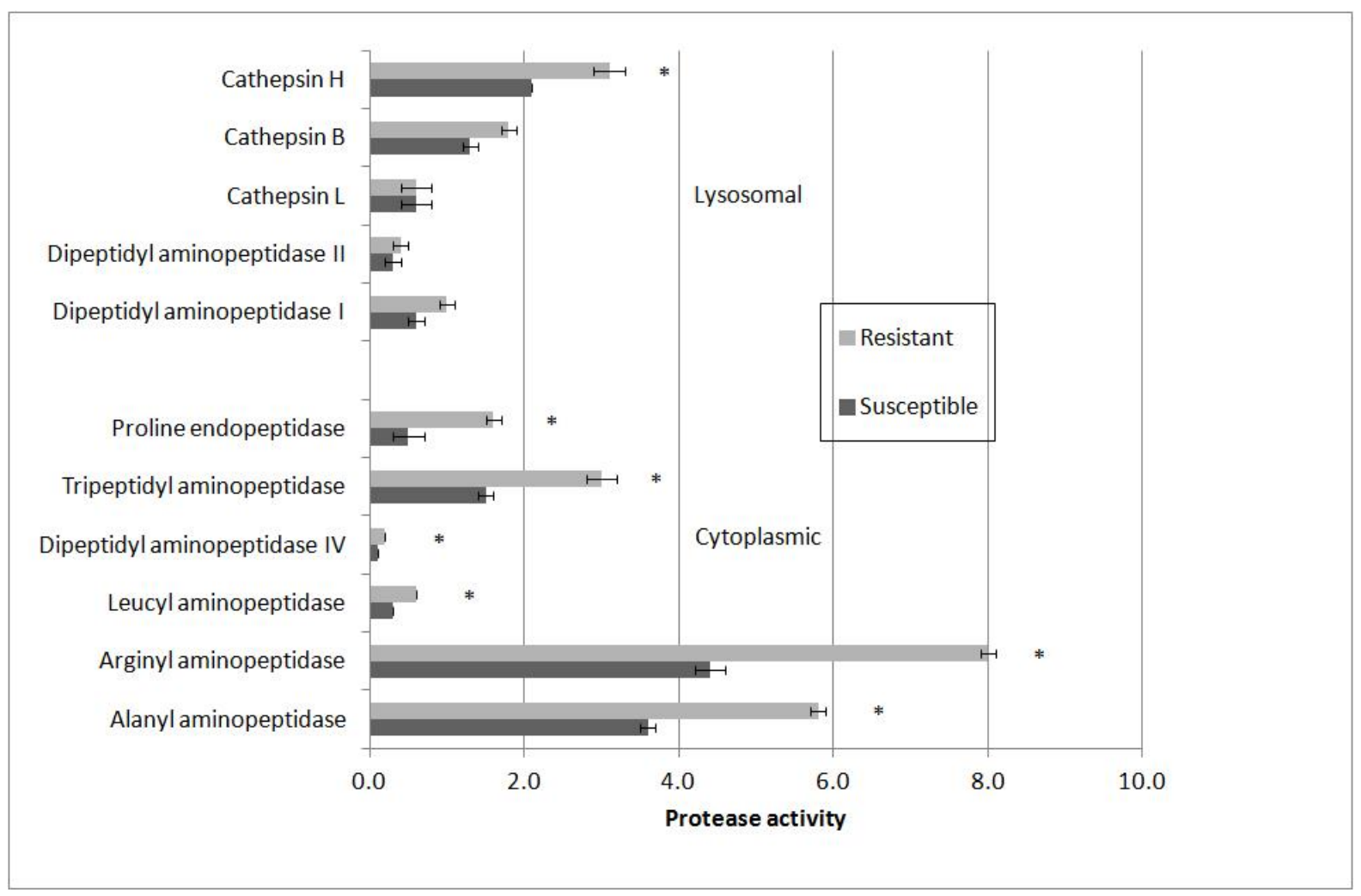

Figure 1. Protease activities ( $\mu$ moles substrate hydrolysed $/ \mathrm{h} / \mathrm{mg}$ soluble protein) in a resistant and a susceptible strain of house fly, Musca domestica, based on whole adult body homogenates. ${ }^{12} *$ significantly different at $P<0.05$, comparing resistant and susceptible strains. Adapted from Ahmed et al ${ }^{12}$
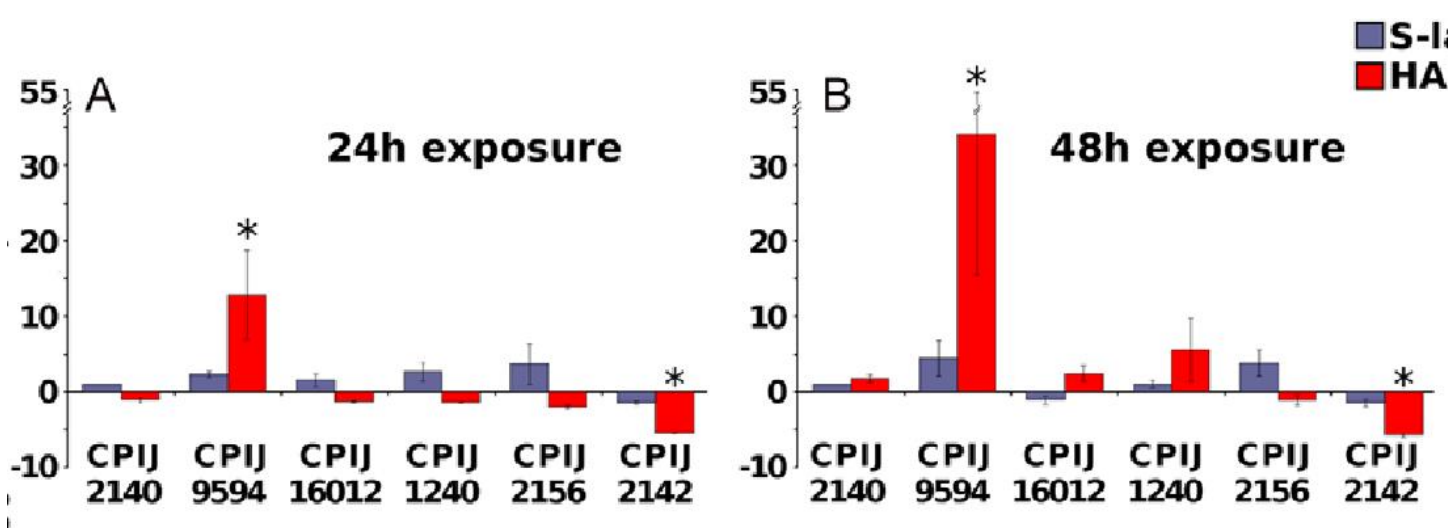

Figure 2. The expression levels (fold change in expression) of protease genes of a permethrin-resistant strain $\left(\mathrm{HAmCq}^{\mathrm{G} 8}\right.$ ) of Culex quinquefasciatus larvae compared to a susceptible (S-lab), following exposure to permethrin (LC50) at A 24 hours and B 48 hours. ${ }^{45}$ Bars above the baseline indicate up-regulation and those below down-regulation.

* $\alpha=0.01$ level of significance. From Reid et al ${ }^{45}$ with permission. (C) 2017 Institute of Zoology, Chinese Academy of Sciences and Wiley 
Table 1. Intracellular protease activities in resistant strains compared to susceptibles

\begin{tabular}{|c|c|c|c|c|c|}
\hline Insect & $\begin{array}{l}\text { Resistance; } \\
\text { strain and } \\
\text { insecticides }\end{array}$ & Treatment $^{a}$ & $\begin{array}{l}\text { Cytoplasmic } \\
\text { protease }^{b} \\
\text { activities: }\end{array}$ & $\begin{array}{l}\text { Lysosomal } \\
\text { protease }^{c} \\
\text { activities: }\end{array}$ & $\begin{array}{l}\text { Refer } \\
\text { ence }\end{array}$ \\
\hline $\begin{array}{l}\text { Musca } \\
\text { domestica } \\
\text { house fly adult }\end{array}$ & $\begin{array}{l}\text { 17bb DDT, } \\
\text { dieldrin }\end{array}$ & DDT 24h- LD50 & $\begin{array}{l}\text { Generally higher in } \\
\mathrm{R}^{\mathrm{d}} \text {, including in all } \\
\text { body parts. }\end{array}$ & $\begin{array}{l}\text { Generally higher in } \\
\mathrm{R}^{\mathrm{d}} \text {, including in all } \\
\text { body parts. }\end{array}$ & 12 \\
\hline $\begin{array}{l}\text { M. domestica } \\
\text { house fly adult }\end{array}$ & $\begin{array}{l}\text { 571ab } \\
\text { fenitrothion }\end{array}$ & $\begin{array}{l}\text { fenitrothion } \\
24 \mathrm{~h}-\text { LD50 }\end{array}$ & $\begin{array}{l}\text { Generally higher in } \\
\text { R. }\end{array}$ & $\begin{array}{l}\text { Generally higher in } \\
\text { R. }\end{array}$ & 13 \\
\hline $\begin{array}{l}\text { M. domestica } \\
\text { house fly adult }\end{array}$ & $\begin{array}{l}571 a b \\
\text { fenitrothion }\end{array}$ & $\begin{array}{l}\text { spinosad } 48 \mathrm{~h}- \\
\text { LD50 }\end{array}$ & $\begin{array}{l}\text { Generally higher in } \\
\text { R. }\end{array}$ & $\begin{array}{l}\text { Generally higher in } \\
\text { R. }\end{array}$ & 14 \\
\hline $\begin{array}{l}\text { Tribolium } \\
\text { castaneum red } \\
\text { flour beetle } \\
\text { adult }\end{array}$ & $\begin{array}{l}\text { CTC-12 } \\
\text { malathion }\end{array}$ & $\begin{array}{l}\text { deltamethrin, } \\
\text { pirimiphos- } \\
\text { methyl and } \\
\text { gamma- } \mathrm{HCH} \\
48 \mathrm{~h}\end{array}$ & $\begin{array}{l}\text { All proteases } \\
\text { higher in } \mathrm{R} \text {. } \\
\text {. }\end{array}$ & $\begin{array}{l}\text { All proteases } \\
\text { higher in } R \text { except } \\
\text { cathepsin } L \text { which } \\
\text { was lower. }\end{array}$ & 15 \\
\hline $\begin{array}{l}\text { T. castaneum } \\
\text { red flour } \\
\text { beetle adult }\end{array}$ & $\begin{array}{l}\text { CTC-12 } \\
\text { malathion }\end{array}$ & $\begin{array}{l}\text { cyfluthrin } 48 \mathrm{~h}- \\
\text { LD50 }\end{array}$ & $\begin{array}{l}\text { All proteases } \\
\text { higher in R } \\
\text { compared to S. }\end{array}$ & $\begin{array}{l}\text { All proteases } \\
\text { higher in } \mathrm{R} \\
\text { compared to } \mathrm{S} \text {. }\end{array}$ & 16 \\
\hline \multicolumn{3}{|c|}{ for responses to insecticide exposure (Part 4) d } & \multicolumn{3}{|c|}{$\mathrm{R}$ resistant strain, $\mathrm{S}$ susceptible strain } \\
\hline $\begin{array}{l}\text { b Cyto } \\
\text { Alany } \\
\text { Arginy } \\
\text { Leucy } \\
\text { Dipep } \\
\text { Triper } \\
\text { Prolin }\end{array}$ & $\begin{array}{l}\text { plasmic proteas } \\
\text { aminopeptidas } \\
\text { l aminopeptidas } \\
\text { aminopeptidas } \\
\text { tidyl aminopept } \\
\text { tidyl aminopep } \\
\text { e endopeptidase }\end{array}$ & $\begin{array}{l}\text { es: }{ }^{12} \\
\text { dase IV } \\
\text { idase }\end{array}$ & $\begin{array}{l}\text { c Lysosomal protease } \\
\text { Dipeptidyl aminopept } \\
\text { Dipeptidyl aminopept } \\
\text { Cathepsin L } \\
\text { Cathepsin B } \\
\text { Cathepsin H } \\
\text { Cathepsin D }\end{array}$ & $\begin{array}{l}12 \\
\text { dase I } \\
\text { dase II }\end{array}$ & \\
\hline
\end{tabular}


Table 2. Comparison of resistant with susceptible strains of insect pests, with up-regulation of intracellular proteases, based on transcriptomic analyses.

\begin{tabular}{|c|c|c|c|c|}
\hline Pest species & Stage(s) & $\begin{array}{l}\text { Strain resistant } \\
\text { to: }\end{array}$ & $\begin{array}{l}\text { Selected up- } \\
\text { regulated } \\
\text { proteases: }\end{array}$ & Reference \\
\hline $\begin{array}{l}\text { Bactrocera oleae, } \\
\text { olive fly }\end{array}$ & $\begin{array}{l}\text { heads of adult } \\
\text { flies }\end{array}$ & spinosad & serine protease & 18 \\
\hline $\begin{array}{l}\text { M. domestica, house } \\
\text { fly }\end{array}$ & $\begin{array}{l}\text { 3-day old } \\
\text { adult female }\end{array}$ & permethrin & protease & 19 \\
\hline $\begin{array}{l}\text { Plutella xylostella, } \\
\text { diamondback moth }\end{array}$ & $\begin{array}{l}\text { eggs, third } \\
\text { instar larvae, } \\
\text { pupae, and } \\
\text { adults }\end{array}$ & $\begin{array}{l}\text { chlorpyrifos, } \\
\text { fipronil }\end{array}$ & trypsin & 20 \\
\hline $\begin{array}{l}\text { Culex } \\
\text { quinquefasciatus, } \\
\text { mosquito }\end{array}$ & $\begin{array}{l}\text { fourth instar } \\
\text { larvae }\end{array}$ & permethrin & serine peptidases & 21 \\
\hline $\begin{array}{l}\text { Myzus persicae, } \\
\text { peach green aphid }\end{array}$ & $\begin{array}{l}\text { adult } \\
\text { wingless }\end{array}$ & pirimicarb & cathepsins & 22 \\
\hline $\begin{array}{l}\text { Anopheles gambiae, } \\
\text { mosquito }\end{array}$ & adult & deltamethrin & peptidase & 23 \\
\hline $\begin{array}{l}\text { Drosophila } \\
\text { melanogaster, fruit } \\
\text { fly }\end{array}$ & adult & DDT & peptidase & 24 \\
\hline $\begin{array}{l}\text { Frankliniella } \\
\text { occidentalis western } \\
\text { flower thrips }\end{array}$ & $\begin{array}{l}\text { first instar, } \\
\text { second instar, } \\
\text { pre-pupae } \\
\text { and pupae, } \\
\text { adult }\end{array}$ & $\begin{array}{l}\text { spinosad, TSWV } \\
\text { infection (virus) }\end{array}$ & $\begin{array}{l}\text { proteosome } \\
\text { (some down- } \\
\text { regulated) }\end{array}$ & 25 \\
\hline $\begin{array}{l}\text { Aedes aegypti, } \\
\text { mosquito }\end{array}$ & $\begin{array}{l}\text { fourth instar } \\
\text { larvae }\end{array}$ & $\begin{array}{l}\text { permethrin, } \\
\text { imidacloprid, } \\
\text { propoxur }\end{array}$ & None & 26 \\
\hline $\begin{array}{l}\text { Bemisia tabaci, } \\
\text { sweet potato } \\
\text { whitefly }\end{array}$ & $\begin{array}{l}\text { eggs, fourth } \\
\text { instar } \\
\text { nymphs, one- } \\
\text { day-old } \\
\text { unmated } \\
\text { adult females }\end{array}$ & thiamethoxam & $\begin{array}{l}\text { cysteine protease, } \\
\text { protease (down- } \\
\text { regulated) }\end{array}$ & 27 \\
\hline $\begin{array}{l}\text { T. castaneum, red } \\
\text { flour beetle }\end{array}$ & adult & phosphine & $\begin{array}{l}\text { cathepsin B } \\
\text { (downregulated) }\end{array}$ & 28 \\
\hline
\end{tabular}


Culex pipiens pallens, female adults deltamethrin mosquito $\mathrm{m} 1$ metalloprotease zinc 29 